\title{
A Model Study of Mobile Applications Stickiness
}

\author{
Fu Jiuqiang \\ Beijing Institute of Technology, Beijing, 100081, China \\ fujq0306@126.com
}

Keywords: model study; mobile applications; stickiness; user experience

Abstract. The purpose of this paper is to study the possible forming reason of stickiness about mobile application from the users' perspective and find the sticky influence factors. Research methods of this study include literature research, normative research, empirical research and evaluation research. This study constructed the user experience model which based on sticky factors form the basic dimensions and the core dimensions. Basic dimension is a basement of mobile applications' producing stickiness, and the core dimension is the driving factor of stickiness. This study also constituted evaluation system of stickiness, and provided a theoretical foundation for developing mobile applications with stickiness characteristics. The outcomes of this study can be exploited to drive further research in the field.

\section{Introduction}

As the rapid spread of mobile terminals, such as smart phones and tablets, completing the basic tasks of life by mobile applications has been gradually accepted by public. Because users in many countries are accustomed to using mobile Internet in free pattern, the mobile apps, as mobile Internet portal, generally provide free versions to users and developers will own profit through the users' using of paid service or placing ads within the mobile app. It is different from direct sales pattern of traditional applications to provide mobile applications by using the free patterns. This pattern not only needs users to download and install software, but also requires users to use target software for a long time, in this way, business or individual developers will own profit through mobile apps. The concern of this article is users' continued behavior after users' choice. Software need not only to attract users, but also to retain users and establish long-term relationships [1]. So, it has become the focus of discussion in relative theory and practice that what features will make mobile apps appeal to users and build long term relationship with users. This is the urgent problem the research wants to solve.

Through the literature review, research will sort stickiness into users' stickiness and applications' stickiness. Users' stickiness aims to analysis of adhesion for mobile application from user's psychology and behavior. Applications' stickiness aims to analysis qualitative characteristics of mobile applications.

\section{Influencing factors of mobile apps users' sticky behavior}

Based on Theory of Planned Behavior. Attitude: Attitude is a solid psychological tendency to particular things, ideas or other people for individual, and it has features of persistence and universality [2]. Subjective Norm: Subjective Norm refers to that when people engage in some behavior, they will automatically be influenced by people and things around, which will enable an individual's behavioral leave their original path, suggesting that personal behavior is subject to external constraints [3]. Custom: People established custom by repeatedly engaging in an activity for a long time, or through constant practice, have adapted to the new situation.

Based on Customer Value Theory. User's Perceived Value: Users can feel the interest and its cost for product or service after the product or service's overall assessment of the effectiveness. Perceived Quality: Perceived quality specifically refers to user-perceived quality of mobile applications. ISO 8042 defines software quality as: product should provide or meet the definite and implied needs [4]. Flow experience: When people engage in their favorite activities, their personal 
attention will be highly concentrated, and they will unconsciously filter out all around events [5]. Switching costs: Switching costs are the customers for some reason abandon their original products or business and incur the cost, in a certain sense, it belongs to a specific investment [6]. Substitute attractions: Research on economics, substitute refers to alternative products to existing products. In marketing research, substitute refers to similar products of other brands.

Platform Services Property. The concept of platform services Properties is proposed from that mobile applications should provide users with services. In this paper, mobile applications are divided into tools and platforms type, tools-application specifically refers to the functionality provided by the application, and software itself will be able to meet the needs of users, the aim of users of using this kind applications is obtained physical and mental pleasure. Platform-application means that applications do not themselves provide value for users, and applications are only part of the service platform. Enterprises can provide users with valuable products or services through the coordination of the various parts of the platform.

\section{Our study}

Research objectives and targets. Our experiments were aimed at studying influencing factors of the stickiness of finding the relationships between different factors. This study is intended for the widest range of ordinary users, through the questionnaire survey of 150 students, exploring sticky factors of mobile apps. About the mobile apps for evaluation, this study selects the 12 highly used products in China, and allow the users to choose freely. According to the data of Apple's official software shop, the selected 12 mobile apps has the highest frequency of downloading in Mobile phones and tablet PC users in China. Those are: TaoBao, WeChat, Tencent QQ, iQIYI, JD, YouKu, mojiWeather, Mito, QQ music, Baidu map, Dianping, Baidu browser.When validating the explanatory power of the theory by using structural equation model, the number of questionnaire samples have certain requirements. When the sample number is less than 100, the theory's reliability of results will be greatly reduced. Nunnally recommended the number of samples is at least 10 times that of variables, that is to say, if your model has 6 variables, sample number is at least 60 . Taking into account the theoretical model in this study, the variables number is 14 , so we position 150 study samples.

Descriptive statistics analysis. In this way, we analyze participants' education, age, career, time and frequency of users of mobile applications, as is shown in table 1. 
Table 1. Descriptive statistics of samples.

\begin{tabular}{|c|c|c|c|}
\hline ITEM & CATEGORY & NUMBER & PERCENTAGE \\
\hline Gender & $\begin{array}{c}\text { Male } \\
\text { Female }\end{array}$ & $\begin{array}{l}67 \\
83\end{array}$ & $\begin{array}{l}44.66 \% \\
55.33 \%\end{array}$ \\
\hline Age & $\begin{array}{l}\text { Under the age of } 18 \\
\text { Age } 18-25 \\
\text { Age } 26-40\end{array}$ & $\begin{array}{c}2 \\
141 \\
7\end{array}$ & $\begin{array}{c}1.33 \% \\
94 \% \\
4.66 \%\end{array}$ \\
\hline Education & $\begin{array}{l}\text { Undergraduate } \\
\text { Postgraduate }\end{array}$ & $\begin{array}{c}123 \\
27\end{array}$ & $\begin{array}{l}82 \% \\
18 \%\end{array}$ \\
\hline App Most Be Used & $\begin{array}{c}\text { WeChat } \\
\text { TaoBao } \\
\text { Tencent QQ } \\
\text { Baidu map } \\
\text { iQIYI } \\
\text { YouKu } \\
\text { Others } 6\end{array}$ & $\begin{array}{c}92 \\
17 \\
13 \\
8 \\
6 \\
5 \\
9\end{array}$ & $\begin{array}{c}61.33 \% \\
11.33 \% \\
8.66 \% \\
5.33 \% \\
4 \% \\
3.3 \% \\
6 \%\end{array}$ \\
\hline $\begin{array}{c}\text { The History of Using } \\
\text { Target App }\end{array}$ & $\begin{array}{l}\text { Under } 3 \text { months } \\
\text { 3-6 months } \\
6 \text { months-1year } \\
\text { 1-2years } \\
\text { More than 2years }\end{array}$ & $\begin{array}{c}7 \\
9 \\
16 \\
58 \\
60\end{array}$ & $\begin{array}{c}4.66 \% \\
6 \% \\
10.66 \% \\
38.66 \% \\
40 \%\end{array}$ \\
\hline $\begin{array}{l}\text { The Length of Time } \\
\text { Using Target App } \\
\text { in One Day }\end{array}$ & $\begin{array}{c}\text { Under } 30 \text { minutes } \\
30 \text { minutes }-1 \text { hour } \\
1 \text { hour }-2 \text { hours } \\
2 \text { hours }-3 \text { hours } \\
\text { More than } 3 \text { hours }\end{array}$ & $\begin{array}{l}33 \\
49 \\
28 \\
26 \\
14\end{array}$ & $\begin{array}{c}22 \% \\
32.66 \% \\
18.66 \% \\
17.33 \% \\
9.33 \%\end{array}$ \\
\hline
\end{tabular}

Structure equation model analysis. Structural equation model is used in the analysis of causal relationships between variables, which will better reflect the impact of explanatory variables. This study used the Amos software to analyze the relationships between variables involved, table 2 showed the model fitting. As being seen from the table, though the fitting index of the model has not reached the ideal value, but the discrepancy is little, it is still within the acceptable range.

Table 2. The results of the model fitting

\begin{tabular}{|c|c|c|c|c|c|c|c|c|}
\hline & Chi-Square & Df & CS/df & $\begin{array}{c}\text { RMSE } \\
\text { A }\end{array}$ & NFI & RFI & IFI & TLI \\
\hline Fitting Result & 757.247 & 19 & 3.965 & 0.106 & 0.76 & 0.71 & 0.81 & 0.77 \\
& & 1 & & & 7 & 9 & 5 & 4 \\
\hline ideal value & - & - & From 2 to 3 & $<0.08$ & $>0.9$ & $>0.9$ & $>0.9$ & $>0.9$ \\
\hline
\end{tabular}

Figure 1 shows the model of this study. From the results, we can generalize from the following aspects. There is positive relationship between perceived application quality and perceived value, perceived application quality and flow experience, flow experience and user-perceived value, perceived value and overall satisfaction of users, flow experience and sticky behavior intention, overall satisfaction and sticky behavior intention, subjective norm and overall satisfaction, habits and sticky behavior intentions, habits and switching costs. There is negative correlation between alternative attractiveness and sticky behavior intention. 


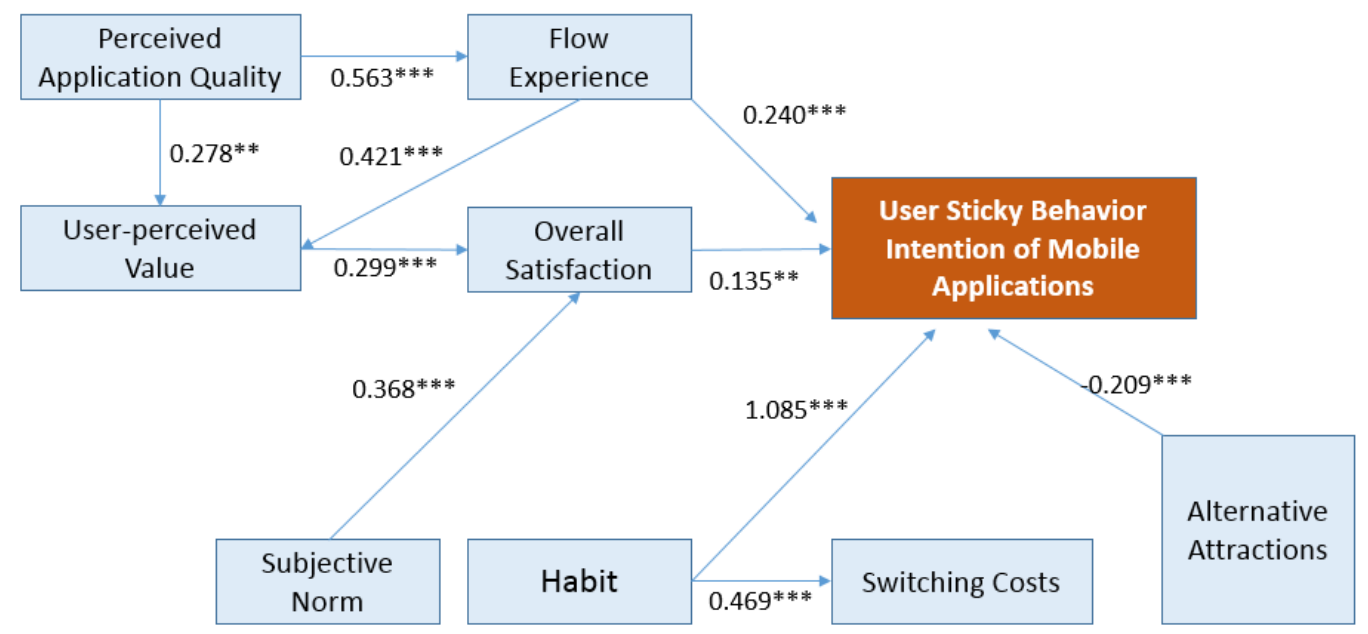

Figure 1. The stickiness model of mobile applications

\section{Conclusions}

This study constructed the user experience model based on sticky factors form basic dimension and core dimension. Basic dimension is a basement and general evaluation criteria of mobile applications which can be accepted by users. As meeting basic dimension, mobile applications should guarantee high quality and be accepted by the user, but does not necessarily have the sticky characteristics. Instead, if mobile applications do not meet the requirements of basic dimension, they will not certainly be accepted by users and cannot generate stickiness. Basic dimension is divided into application using quality and product quality. Core dimension is the driving and necessary factor for mobile application stickiness. The study has supplied the deficiency of stickiness research for the existing mobile apps and contributed to a better understanding of mobile users' behavior. Through analyzing mobile applications' user experience pattern and influencing factors of stickiness, the study also constituted evaluation system of user experience pattern and provided a theoretical foundation and practice of guarantee for developing mobile applications with stickiness characteristics. Application developer can allocate of appropriate resources based on the conclusions of the index system, making different design strategies in order to achieve the business objectives.

\section{References}

[1] Wang Haiping. Study on online consumer stickiness [D].Shandong University, 2009.103-121.

[2] Ajzen, I., \& Fishbein, M. (1977). Attitude-behavior relations: A theoretical analysis and review of empirical research. Psychological Bulletin, 84, 888-918.

[3] Levin, A.M., M. C. Dato-on and C. Manolis. 2007. "Deterring Illegal Downloading: The Effects of Threat Appeals, Past Behavior, Subjective Norms, and Attributions of Harm." Journal of Consumer Behaviour, 6: 111-22.

[4] ISO, ISO 8042 [EB/OL]. (1998-3)[2015-3-20].

[5] Csikszentmihalyi, M.: Beyond boredom and anxiety: Experiencing flow in work and play. Jossey-Bass, San-Francisco (2000).

[6] Klemperer P (1987) Markets with consumer switching costs. Q J Econ 102:375-394. 